\title{
Geriatri poliklinik olgularında geriatrik sendromlar: 1048 olgunun analizi
}

\author{
Geriatric syndromes in the geriatric outpatient clinic subjects: Analysis of 1048 cases \\ Derya Kaya Süleyman Emre Koçyiğit Özge Dokuzlar Pınar Soysal Ahmet Turan Işık \\ Dokuz Eylül Üniversitesi Tıp Fakültesi, Geriatri Bilim Dalı, Yaşlanan Beyin ve Demans Ünitesi, İzmir, \\ Türkiye
}

\section{Öz}

Amaç: Bir Geriatri merkezinde düzenli takip edilen hastaların sosyodemografik değişkenlerini, klinik durumlarını ve geriatrik sendromları değerlendirmek.

Gereç ve Yöntem: Geriatri polikliniğimizde Ocak 2013 ve Aralık 2015 yılları arasında düzenli takip edilen 1048 olgunun tıbbi kayıtları geriye dönük gözden geçirildi. Olguların yaş, cinsiyet, eğitim yılı, nörokognitif durum, duygu durum, günlük yaşam aktiviteleri, denge ve yürüme, nutrisyonel durumu da içeren Ayrıntılı Geriatrik Değerlendirme bilgileri, tanıları, kullanılan ilaç sayısı kaydedildi.

Bulgular: Olguların ortalama yaşı 77.4 \pm 6.8 olup \%37.2'si erkek ve \%62.8'i kadındı. \%54.2'si evli ve \%78.8'i en az 5 yıllık eğitime sahipti. 1048 olgunun \%78.8'i non-demans olgularıydı ve \%15.2'sinde Alzheimer hastalığı vardı. Olgularda polifarmasi (\%59.8), üriner inkontinans (\%44.1), ağrı (\%41.8) ve uyku bozuklukları (\%40.8) gibi geriatrik sendromlar bulunmaktaydı.

Sonuç: Yaşlı olgularda geriatrik sendromların değerlendirilmesi, hasta çıktılarının daha iyi olmasına neden olup, hastaların yaşam kalitesinin yükseltilmesi ve kişileştirilmiş tedavilere yardımcı olması bakımından önemlidir.

Anahtar Sözcükler: Geriatrik sendrom, polifarmasi, üriner inkontinans, ağrı, uyku bozuklukları, düşme.

\section{Abstract}

Aim: To assess sociodemographic variables, clinical conditions and geriatric sydromes of patients who were followed up in a Geriatrics center.

Materials and Methods: The medical records of 1048 patients who were regularly followed up in our geriatric outpatient clinic, between January 2013 and December 2015 were retrospectively reviewed. Age, gender, education year, diagnosis, number of drug used and data of compherensive geriatric assessment including neurocognitive status, mood, daily living activities, gait and balance, nutrition were recorded.

Results: The mean age of the cases was $77.4 \pm 6.8$ of whom $37.2 \%$ were male and $62.8 \%$ female. $54.2 \%$ of them were married and $78.8 \%$ had education for at least 5 year. It was shown that $63 \%$ of 1048 patients were nondementia cases and $15.2 \%$ had Alzheimer's disease. Geriatric syndromes such as polypharmacy (59.8\%), urinary incontinence (44.1\%), pain (41.8\%), sleep disorders (40.8\%) were found among the subjects.

Conclusion: Assessment of geriatric syndromes in the care of older patients are important to improve the quality of life significantly and help personalize management, leading to better patient outcomes.

Keywords: Geriatric syndrome, polypharmacy, urinary incontinence, pain, sleep disorders, falls.

\footnotetext{
Yazışma Adresi: Ahmet Turan Işık

Dokuz Eylül Üniversitesi Tıp Fakültesi, Geriatri Bilim Dalı,

Yaşlanan Beyin ve Demans Ünitesi, İzmir, Türkiye

Makalenin Geliş Tarihi: 28.12.2016 Kabul Tarihi: 14.02.2017
} 


\section{Giriş}

Yaşlı bireyler tarih boyunca zaman zaman farklı bir yerde konumlandırılmaya çalışılmışlardır. Hippocrates ve Cicero yaşlanma ve sağlık üzerine yazılar kaleme almışlar, 1881 'de Charcol nun yaşlanma üzerine ilk tıbbi ders kitabı yayınlanmıştır (1). 'Geriatri' kelimesi 1909'da Ignatz Leo Nascher tarafından kazandırılmıştır. Nascher 1909'da New York Medical Journalda yayınlanan makalesinde, yaşı anlamına gelen geras ve hekim anlamına gelen iatrikos kelimelerinin birleşimi olan Geriatri teriminin dil bilgisine yeni bir kelime olarak önerir, yaşlılığın ve hastalıklarının tıpta ayrı bir yerinin olması gerektiğini bildirir (2). Daha sonra geriatrinin babası olarak anılacak olan Nascher 1914'te geriatrik tıbbın ilk Amerikan ders kitabını, Geriatrics: The Diseases of Old Age and Their Treatment, yayınlamıştır (3). Geriatri, modern sağlık sistemi içinde özelleşmiş ayrı bir bilim dalı olarak ilk kez 1948'de Birleşik Krallık'ta kurulmuştur (4). Günümüzde yaşlı olguların sağlık sorunları, hastalıkları, sosyal ve fonksiyonel yaşamları, hayat kalitesi, sağlıklı yaş alma süreçleri, koruyucu hekimlik uygulamaları ile ilgilenen bir bilim dalıdır (5).

Dünyada olduğu gibi, ülkemizde de yaşlı nüfusun oranının giderek arttığı yadsınamaz bir gerçektir. Yaşlı bireylerin hastalık seyirleri ve prezantasyon bulguları erişkinlerden farklıdır, hastalıkların dağılımı, sıklığı, tedavi algoritmaları, koruyucu uygulamalar tahmin edildiğinden daha fazla özellik arz eder. Yaşı bireylerin yaşadığı sosyal-hukuksal sorunlar azımsanmayacak ölçüdedir. Geriatrik olgular yaşlı olgunun tek bir hastalık başlığı altında tanımlanamayan multifaktöriyel kaynaklı birbiriyle etkileşen bir dizi semptom şemsiyesi olarak ifade edilebilen "geriatrik sendrom" olarak adlandırılan özellikli durumlara sahip olabilirler (6). Yaşlı bireylerin sağlıklı yaş almaları ve bu sürecin idamesi, hastalıklarının tanınması, zamanında ve etkili müdahale edilmesi, sosyodemografik, klinik değişkenlerinin ve sahip oldukları geriatrik sendromların bilinmesi ile başlayan araştırmalarla etkinlik kazanmaktadır. Yaşlı olgularda geriatrik sendromların değerlendirilmesinin özellikle sıklığının belirlenmesinin geriatrik bir hastanın sahip olduğu multifaktöriyel bu sendromların farkındalığını artıracağını, hastaların yaşam kalitesinin yükseltilmesi ve kişileştirilmiş tedavilerde öncelikli hedeflerin belirlenmesi açısından önemli olabileceğini ve belki de daha önemlisi sendromların gelişimini azaltıcı/önleyici bir takım stratejilerin, sağlık politikalarının geliştirilmesine (polifarmasi ile mücadele, düşmelerin önlenmesi, vb.) yardımcı olabileceğini düşünmekteyiz. Bu nedenle, bu çalışmada Ocak 2013Aralık 2015 tarihleri arasında Dokuz Eylül Üniversitesi Tıp Fakültesi Geriatri Bilim Dalına başvuran olguların tıbbi kayıtlarının geriye dönük incelenerek hastaların geriatrik sendrom özelliklerinin incelenmesi amaçlanmıştır.

\section{Gereç ve Yöntem}

Çalışmadaki veriler 1 Ocak 2013-31 Aralık 2015 tarihleri arasında başvuran bireylere ait birim dosyalarının geriye dönük olarak incelenmesinden elde edildi. Verilerin istatistiksel değerlendirilmesi SPSS 17.0 programı kullanılarak gerçekleştirildi. Olguların yaş, cinsiyet, eğitim yılı, nörokognitif durum, duygu durum, günlük yaşam aktiviteleri, denge ve yürüme, nutrisyonel durumu da içeren Ayrıntılı Geriatrik Değerlendirme (AGD) bilgileri, tanıları, kullanılan ilaç sayısı kaydedildi. Elde edilen bulgular istatistiksel olarak frekans dağılımı yönünden irdelendi ve benzer çalışma sonuçlarıyla karşılaştırıldı.

\section{Bulgular}

Geriatri Bilim Dalının 1 Ocak 2013-31 Aralık 2015 tarihleri arasında toplam 1947 olgunun poliklinik kaydı saptandı. Dosyada yetersiz veri, yer değişikliği, vefat, izlem yetersizliği gibi nedenlerle olgular dışlandıktan sonra tüm verileri eksiksiz girilmiş ve düzenli izlemde olan toplam 1203 olgu değerlendirmeye alındı. Olguların \%12.9'u 55-65 yaş arasında idi, çalışmanı ana teması geriatrik sendromlar olması nedeniyle 155 olgu da çalışma dışında tutuldu. $\mathrm{Bu}$ nedenle toplam 1048 olgunun dosya kayıtları analiz edildi. Olguların \%41'i (430 olgu) 65-75 yaş, \%46.2'si (484 olgu) 75-85 yaş ve $\% 12.8$ 'i (134 olgu) 85 yaş üzerindeydi. Hastaların \%37.2'si (390 olgu) erkek, \%62.8'i (658 olgu) kadındı. Eğitim durumları bakımından, olguların \%12'si okuryazar değildi, \%9.2'si okur-yazar, \%36'sı ilkokul mezunu, \%9.4'ü ortaokul mezunu, \%16.2'si lise mezunu, \%17.1'i üniversite mezunu olarak belirlendi. Değerlendirmeye alınan bireylerin \%1.1'i bekar, \%54.2'si evli, \%2.1'i eşinden boşanmış, \%42.7'si duldu. Kadın olguların $\% 35.7$ 'si, erkek olguların ise \%85.8'i evli olarak kaydedildi. "Unutuyorum" diyerek başvuran toplam 858 olgu (\%81.9) olduğu belirlendi. "İdrar kaçırıyor musunuz?" sorusuna olguların \%9.35'inin (98 olgu) evet şeklinde cevap verdiği saptandı. Ayrıntılı Geriatrik Inceleme'de, olguların mini-mental durum değerlendirmesi (MMSE) ortalama skoru 23.4 \pm 5.9 , kognitif durum test (COST) ortalama skoru 22.0 \pm 6.3 , Montreal Kognitif Değerlendirme Test (MoCA) skoru ortalaması $21.5 \pm 5.2$ saptandı. Tanısal açıdan bakıldığında, olguların \%63'ü (661 olgu) non-demans, \%15.2'sinde (160 olgu) Alzheimer Hastalığı (AH), \%6.5'u (69 olgu) mikst tip demans, \%4.1'i (43 olgu) Lewy Cisimcikli Demans (LCD), \%2.9'ü (30 olgu) vasküler demans, \%1.8'sinde (18 olgu) frontotemporal demans (FTD), \%0.3'ünde (3 olgu) progresif supranükleer palsi (PSP), \%0.2'sinde (2 olgu) multisistem atrofi (MSA), $\% 6$ 'sında (62 olgu) hafif kognitif bozukluk (HKB) tanıları ile izlenmekteydi. Olguların sosyodemografik ve AGD verileri Tablo-1'de gösterilmiştir. 
Olgular geriatrik sendromlar açısından gözden geçirildiğinde, en sık görülen durum polifarmasi (\%59.8) olarak saptanırken, polifarmasi oranı AGD sonrası \%43.2'ye geriledi. Olguların ilk başvurularındaki ve 6.ay sonraki kontroldeki (AGD sonrası) ilaç sayısı da Tablo1 'de yer almaktadır. Geriatrik sendromlardan üriner inkontinans (\%44.1), ağrı (\%41.8) ile diğer geriatrik sendromlar Tablo-2'de verilmiştir.

Tablo-1. Olguların Demografik ve Ayrıntılı Geriatrik Değerlendirme Parametre Özellikleri.

\begin{tabular}{ll}
\hline \multicolumn{2}{c}{ DEMOGRAFIK ÖZELLiKLER } \\
\hline Yaş & $77.4 \pm 6.8(65-98)$ \\
Cinsiyet (K/E) & $658 / 390$ \\
Eğitim (yıl) & $7.0 \pm 4.6(0-21)$ \\
VKI & $28.4 \pm 4.4$ \\
\hline AYRINTILI GERIATRIK DEĞERLENDiRME \\
\hline MMSE & $23.4 \pm 5.9(0-30)$ \\
COST & $22.0 \pm 6.3(0-30)$ \\
MoCA & $21.5 \pm 5.2(0-30)$ \\
GDS & $3.6 \pm 3.5(0-15)$ \\
SÇT & $3.6 \pm 1.5(0-5)$ \\
TGYAT & $86.9 \pm 19.3(0-100)$ \\
EGYAT & $10.4 \pm 5.4(0-22)$ \\
POMA & $22.6 \pm 6.2(0-28)$ \\
MNA & $10.9 \pm 2.6(0-14)$ \\
Charlson KI & $1 \pm 1(0-5)$ \\
İlaç sayısı 1 & $5.6 \pm 3.3(0-19)$ \\
İlaç sayısı 2 & $4.9 \pm 2.4(0-13)$ \\
\hline
\end{tabular}

E: Erkek, K: Kadın, VKI: Vücut Kitle İndeksi, Charlson KI: Charlson Komorbidite İndeksi, MNA: Mini Nutrisyonel Değerlendirme, POMA Performansa Yönelik Mobilite Değerlendirmesi, EGYAT: Enstrümental Günlük Yaşam Aktiviteleri Testi, TGYAT: Temel Günlük Yaşam Aktiviteleri Testi, SÇT: Saat Çizme Testi, GDS: Geriatrik Depresyon Skalası, MoCA: Montreal Kognitif Değerlendirme, COST: Kognitif Durum Testi, MMSE: Minimental Durum Değerlendirmesi

*Değerler; Ortalama $\pm S S$ (Aralık Değerler)'dir.

Tablo-2. Olgularda Görülen Geriatrik Sendromlar.

\begin{tabular}{ll}
\hline Sendrom & $\mathbf{n}(\%)$ \\
\hline Demans & $357(34)$ \\
Polifarmasi & $596(59.8)$ \\
Ortostatik hipotansiyon & $275(26.2)$ \\
Malnutrisyon & $190(18.1)$ \\
Bası yaraları & $19(1.8)$ \\
Üriner inkontinans & $443(44.1)$ \\
Düşme & $346(34.4)$ \\
Uyku Bozuklukları & $401(40.8)$ \\
Ağrı & $412(41.8)$ \\
Konstipasyon & $291(29.7)$ \\
Tremor & $221(21)$ \\
Depresyon & $328(32.6)$ \\
\hline
\end{tabular}

\section{Tartışma}

Retrospektif tanımlayıcı bu çalışmada hastalar geriatrik sendromlar açısından gözden geçirildiğinde, en sık görülen durum polifarmasi olarak saptandı. Polifarmasiyi takip eden geriatrik sendromlar üriner inkontinans, kronik ağrı ve uyku bozukluklarıydı. Değerlendirmeye aldığımız olguların \%81.9'u unutkanlık yakınması ile başvururken olguların yalnızca \%34'ünde demans belirlendi. Toplumda yaşayan 55 yaş ve üstü bireylerin dahil edildiği Eskişehir'de yürütülen toplum tabanlı bir çalışmada demans prevalansı tüm kohortun \%8.4'ünde, 75 yaş ve üstü grubun \%30.4'ünü oluşturmaktaydı (7). Çalışmamızda olguların ortalama yaşı 77 olmakla birlikte demans oranının yüksek bulunması kliniğimizin bir referans demans merkezi olmasından kaynaklandığını düşünmekteyiz. Olgularımızda en fazla saptanan demans tipi $\mathrm{AH}$ olmakla beraber $\mathrm{AH}$ 'yi miks tip demanslar, LCD, vasküler demans ve FTD takip etmektedir. Florida Beyin Bankası'nda postmortem kesin tanısı konmuş 382 olgunun değerlendirildiği bir çalışmada demansların sıralaması ise \%77'sinde $\mathrm{AH}$, \%26'sında LCD, \%5'inde FTD olarak bildirilmiştir (8). Kliniğimizin nörodejeneratif demansların sıklık sıralaması literatür ile uyumlu görülmektedir.

Polifarmasi, hem diğer geriatrik sendromlara ve komorbit durumlara eşlik etmesi hem de bu durumların seyrini etkilemesi potansiyeli nedeniyle oldukça önemli bir geriatrik sendromdur. Yapılan çalışmalarda polifarmasinin ilaç-ilaç etkileşim riskini arttırdığı, hastailaç uyumunu bozduğu, beslenme bozukluklarının sık görüldüğü, düşme risk artışı, üriner inkontinans sıklığı ve kognitif bozuklukla ilişkili olduğu gösterilmiştir $(9,10)$. Sistematik bir derlemede polifarmasi oranı hospitalize edilmemiş evde yaşayan geriatrik olgularda \%27-59, uzun dönemli bakım evlerinde \%38-91 olarak raporlanmıştır (11). Bununla birlikte polifarmasinin yaşla birlikte artış gösterdiği artık genel kabul görmüş bir gerçektir (12-15). Çalışmamızda olguların ilk başvurularında polifarmasi oranı yaklaşık \%59.8'di, AGD sonrası ilk vizitte bu oranın \%43.2'ye gerilediği belirlenmiştir. Bu bulgu AGD'nin geriatrik olguların medikal değerlendirmeleri için ne kadar etkili bir araç olduğunu vurgulamaktadır. Polifarmasi sıklığının ve kullanılan ilaç sayısının ilk vizitle birlikte yapılan AGD sonrası azalması Sergi ve ark. ile Lampela ve ark. sonuçları ile uyumluluk göstermektedir $(16,17)$.

Olgularımızda sık görülen diğer geriatrik semptom üriner inkontinanstı. Üriner inkontinans, bütün yaşlarda ve her iki cinsiyette de görülebilen, yaşla sıklığı artan, artmış düşme riski ile bağımsız olarak ilişkilendirilmiş ve maliyet yükü getiren bir geriatrik sendrom olması bakımından önemlidir. Ayrıca çalışmamızda "İdrar kaçırıyor musunuz?" sorusuna \%9.3 oranında evet cevabı alınırken AGD sonrası üriner inkontinans sıklığı \%44.1 olarak saptanmış olması oldukça dikkat çekicidir. Bu 
nedenle geriatrik olguların değerlendirilmesinde inkontinans konusunda daha ayrıntılı sorgulanması önem arz etmektedir. Literatürde üriner inkontinans sıklığı 60 yaş üzeri erkeklerde \%11-34, kadınlarda \%1350 , bakım evinde yaşayanlarda \%43-80 arasında bildirilmektedir (18).

Olgularımızın yaklaşık \%40'ında olduğu belirlenen geriatrik sendromlar kronik ağrı ve uyku bozukluklarıydı. Osteoartrit, kemik ve eklem bozuklukları, kanser ve kronik hastalıklarla ilişkili-ağrı en sık etiyolojik nedenlerdir (19). Toplumda yaşayan yaşlı bireylerde \%25-50 sıklıkta arasında ağrı sorunları olduğu bildirilmiştir (20). Bu durumun bakım evinde kalan yaşlıların \%45-80'inde olduğu tahmin edilmektedir (21). Yaşlılarda ağrının tanınması ve tedavisi ayrı bir öneme sahiptir; yaşlılar ağrının yaşlanmanın doğal bir sonucu olduğunu düşünerek bunu dile getirmeyebilirler, oysa ağrı uyku bozuklukları başta olmak üzere, sosyal izolasyona, immobiliteye, depresyona neden olmaktadır (22).

Yaş ilerledikçe uyku profili de değişir ve uyku bozuklukları görülme sıklığı da artar. Çalışmamızda birincil ve ikincil uyku bozuklukları birlikte ele alındı. Yaşlı kimselerin yaklaşık yarısının uykuyu başlatma ya da sürdürme sorunu olduğu bildirilmiştir. Yaşla birlikte medikal hastalıkların sıklığında ve kullanılan ilaç sayısında artış, yaşla ilişkili sirkadien ritm değişiklikleri, çevresel ve yaşam tarzı değişiklikleri meydana gelmektedir (23). Çalışmamızda her 5 olgudan 2'si uyku bozukluğuna sahiptir ve bu durum komorbid durumlardan bağımsızdır. Bu bulgu geriatrik olguların değerlendirilmesinde mutlaka uyku bozukluklarının da ele alınmasının gerekliliğinin altını çizmektedir.

Kohortumuzda yaklaşık her üç geriatrik olgudan birinde gözlenen düşme diğer sık görülen bir geriatrik sendromdu. Kendi evinde yaşayan 65 yaş üstü nüfusun yaklaşık 1/3'ünün her yıl düşme yaşadığı, bu olguların 1/4'ünde düşmenin tekrarladığı bildirilmiştir. Yaşlılarda düşmelerin yaralanma olmasa dahi uzun süre düştükleri pozisyonda kalmaya ikincil dehidratasyon, hipotermi, bası yaraları, pnömoni gelişebilmektedir. Bir düşme sonrası yaşlıların yaklaşık yarısı düşme korkusuna kapılmakta, 1/4'ü günlük aktivitelerini kısıtlamaktadır (24). Geriatrik sendromlar içinde düşmenin ayrı bir öneme sahip olduğunu ve uygulanacak basit önlemler ya da verilecek eğitim programları (kamu spotları, ülke çapındaki kampanyalar, vb.) ile bu sıklığın azaltılabileceği kanısındayız. Çalışmamızda sıklık sırasına göre gözlenen diğer önemli geriatrik sendromlar; depresyon, konstipasyon, ortostatik hipotansiyon, malnutrisyon, tremor ve bası yaralarıydı. Geriatrik olgular bu açılardan yakınmalarını spontan dile getirmeseler bile her vizitte mutlaka sorgulanmalı, muayene edilmeli, ilgili ölçeklerle somutlaştırılıp gözden geçirilmelidir ve takip edilmelidirler.

Çalışmamızın güçlü tarafları ve bunun yanı sıra sınırlılıkları da bulunmaktadır. Ülkemizde şimdiye kadar AGD ile yapılmış bu kadar geniş olgu serisinin sunulduğu bir çalışma bulunmamaktadır. Çalışmamızın sınırıııkları ise olguların tek merkez kaynaklı olması, toplum temelli olmayıp sadece üçüncü basamağa ulaşabilmiş olgular olması ve retrospektif doğasıdır.

\section{Sonuç}

Çalışmamız bir geriatri merkezinin izlediği olguların sosyodemografik, klinik, geriatrik sendrom özelliklerini yansıtması ve geriatrik olguların öncelikli ve özellikli durumlarının belirlenebilmesine imkan vermesi bakımından önemlidir. Ülkemizde yürütülen sağlık politikalarının düzenlenmesinde çalışmamızın sonuçlarının ışık tutacağı düşünülmektedir

\section{Kaynaklar}

1. Charcot JM. Clinical lecture on senile and chronic diseases. London, New Sydenham Society, 1881

2. Nascher IL. Geriatrics. N Y Med J 1909;90:358-9.

3. Nascher IL. Geriatrics: The Diseases of Old Age and Their Treatment. Philadelphia, P. Blakiston's Son\&Co; 1914

4. Strasser DC. Geriatric rehabilitation: Perspectives from the United Kingdom. Arch Phys Med Rehabil 1992;73(6):582-6.

5. Evans JG. Geriatric medicine: A brief history. BMJ 1997;315(7115):1075-8.

6. Inouye SK, Studenski S, Tinetti ME, Kuchel GA. Geriatric syndromes: Clinical, research and policy implications of a core geriatric concept. J Am Geriatr Soc 2007;55(5):780-91.

7. Arslantas D, Oezbabalik D, Metintas S, et al. Prevalence of dementia and associated risk factors in Middle Anatolia, Turkey. $J$ Clin Neurosci 2009;16(11):1455-9.

8. Barker WW, Luis CA, Kashuba A, et al. Relative frequencies of Alzheimer disease, Lewy body, vascular and frontotemporal dementia, and hippocampal sclerosis in the State of Florida Brain Bank. Alzheimer Dis Assoc Disord 2002;16(4):203-12.

9. Mallet L, Spinewine A, Huang A. The challenge of managing drug interactions in elderly people. Lancet 2007;370(9582):185-91.

10. Hajjar ER, Cafiero AC, Hanlon JT. Polypharmacy in elderly patients. Am J Geriatr Pharmacother 2007;5(4):345-51.

11. Elmståhl S, Linder H. Polypharmacy and inappropriate drug use among older people: A systematic review. Healthy Aging Clin Care Elder 2013;5(1):1-8.

12. Salazar JA, Poon I, Nair M. Clinical consequences of polypharmacy in the elderly: Expect the unexpected, think the unthinkable. Expert Opin Drug Saf 2007;6(6):695-704.

13. Jyrkka J, Enlund H, Lavikainen P, Sulkava R, Hartikainen S. Association of polypharmacy with nutritional status, functional ability and cognitive capacity over a three-year period in an elderly population. Pharmacoepidemiol Drug Saf 2010;20(5):514-22. 
14. Fletcher PC, Berg K, Dalby DM, Hirdes JP. Risk factors for falling among community-based seniors. J Patient Saf 2009;5(2):616.

15. Nuotio M, Jylha M, Luukkaala T, Tammela T. Health problems associated with lower urinary tract symptoms in older women. Scand J Prim Care 2005;23(4):209-14.

16. Sergi G, De Rui M, Sarti S, Manzato E. Polypharmacy in the elderly: can comprehensive geriatric assessment reduce inappropriate medication use? Drugs Aging 2011;28(7):509-18.

17. Lampela P, Hartikainen S, Lavikainen P, Sulkava R, Huupponen R. Effects of medication assessment as part of a comprehensive geriatric assessment on drug use over a 1-year period: a population-based intervention study. Drugs Aging 2010;27(6):507-21.

18. Faltin DL. Epidemiology and definition of female urinary incontinence. J Gynecol Obstet Biol Reprod (Paris) 2009; 38(8 Suppl):146-52.

19. Olmez N. Osteoarthritis. In: Isik AT, Mas RM, Karan MA, Grossberg GT (eds). New Horizons in the Geriatric Medicine. Volume 2. Nova Science Pub Inc; 2013: 246-90.

20. Gloth FM III. Pain management in older adults: Prevention and treatment. J Am Geriatr Soc 2001;49(2):188-99.

21. Ferrell BA, Ferrell BR, Osterweil D. Pain in the nursing home. J Am Geriatr Soc 1990;38(4):409-14.

22. Tekin L, Ata E. Osteoartrit. In: Işık AT, Çelik T (eds). Geriatri Pratiğinde İlaç Tedavisi. 1. Baskı. İzmir: O’Tıp Kitabevi; 2015: 33551.

23. Roepke SK, Ancoli-Israel S. Sleep disorders in the elderly. Indian J Med Res 2010;131:302-10.

24. Studenki S, Swearingen JV. Falls. In: Fillit HM, Rockwood K, Young J (eds). Brocklehurst's Textbook of Geriatric Medicine and Gerontology, $8^{\text {th }}$ ed. Elseiver; 2017:864-72. 